http://dx.doi.org/10.1590/1678-4162-8241

Arq. Bras. Med. Vet. Zootec., v.69, n.5, p.1311-1318, 2017

\title{
Desempenho e características de carcaça de três genótipos comerciais de frangos de corte alimentados com diferentes dietas
}

\author{
[Performance and carcass traits of three commercial broiler genotypes \\ fed different diets]
M.T.P. Silva ${ }^{1}$, R.C. Veloso ${ }^{2 *}$, A.V. Pires ${ }^{1}$, R.A. Torres Filho ${ }^{3}$, S.R.F. Pinheiro ${ }^{1}$, L.K. Winkelstroter ${ }^{4}$, F.J.M. Barros ${ }^{3}$, J.A.B. Senna ${ }^{1}$ \\ ${ }^{1}$ Universidade Federal dos Vales do Jequitinhonha e Mucuri - Teófilo Otoni, MG \\ ${ }^{2}$ Universidade Federal de Viçosa - Viçosa, MG \\ ${ }^{3}$ Universidade Federal Fluminense - Niterói, RJ \\ ${ }^{4}$ Universidade Federal de Minas Gerais - Belo Horizonte, MG
}

\begin{abstract}
RESUMO
Este estudo teve como objetivo avaliar o desempenho e as características de carcaça de frangos de corte de três genótipos comerciais do nascimento aos 35 dias de idade. Utilizou-se um total de 2.970 pintos de três genótipos de aves comerciais (Cobb 500, Hubbard Flex e Ross 308). Os programas nutricionais foram dieta basal, dieta com $10 \%$ mais e $10 \%$ menos de aminoácidos do que a dieta basal. As aves foram distribuídas em delineamento inteiramente ao acaso, em esquema fatorial 3x3 32 (genótipo $\mathrm{x}$ dieta $\mathrm{x}$ sexo), com cinco repetições e 33 aves por unidade experimental. Conversão alimentar, ganho de peso diário, ingestão da dieta e peso corporal aos 35 dias de idade foram registrados. Duas aves de cada unidade experimental foram amostradas e abatidas aos 35 dias de idade para avaliar as seguintes características de carcaça: peso corporal no momento do abate, peso da carcaça e rendimento, e peso e rendimento dos cortes (peito, pernas e asas). Houve uma interação significativa entre o genótipo e sexo para GPD e PC35. Os machos apresentaram melhores desempenhos e características de carcaças do que as fêmeas.
\end{abstract}

Palavras-chave: Cobb, conversão alimentar, Hubbard, rendimento de carcaça, Ross

\begin{abstract}
This study aimed to evaluate performance and carcass traits of three commercial broiler genotypes from hatch to 35 days of age. A total of 2,970 sexed one day old chicks of three commercial broiler genotypes (Cobb 500, Hubbard Flex and Ross 308) were used. The nutritional programs were basal diet, diet with 10\% more and $10 \%$ less amino acids than the basal diets. Birds were distributed in a completely randomized experimental design in a $3 \times 3 \times 2$ (genotype $x$ diet $x$ sex) factorial scheme, with five replicates and 33 birds per experimental unit. Feed conversion, daily weight gain, diet intake and body weight at 35 days of age were recorded. Two birds from each experimental unit were sampled and slaughtered at 35 days of age to evaluate the following carcass traits: slaughter body weight, carcass weight and yield, and main cuts (breast, legs and wings) weight and yield. There was a significant interaction between genotype and sex for ADG and BW35. Males fed basal diets presented higher performance and carcass traits in comparison to females.
\end{abstract}

Keywords: cobb, feed conversion, Hubbard, carcass yield, Ross

\section{INTRODUÇÃO}

O progresso genético na taxa de crescimento, na conversão alimentar e no rendimento de carne torna-se sempre um desafio do ponto de vista nutricional, além de os genótipos predominantes

Recebido em 3 de março de 2015

Aceito em 15 de novembro de 2015

*Autor para correspondência (corresponding author)

E-mail: velosozootecnista@yahoo.com.br na produção de frangos de corte apresentarem diferentes velocidade de crescimento e rendimento de carne (Moreira et al., 2004 e Santos et al., 2005). As exigências do mercado são crescentes com relação aos produtos avícolas, o qual busca maior rendimento de carcaças, de cortes e de produtos processados para os diferentes genótipos (Lima et al., 2008). 
Dessa forma, o melhoramento genético tem permitido melhorias nos sistemas de produção, principalmente quando se trata de redução à idade ao abate, alteração das exigências nutricionais dos indivíduos, melhor conversão alimentar, maior rendimento de carcaças e maior conteúdo de carne magra nas carcaças (Vieira et al., 2007). Assim, a escolha do genótipo deve ser feita de acordo com o interesse de mercado, pois há diferenças no desempenho e no rendimento de carcaça e dos cortes.

Com o melhoramento genético, vem a necessidade de se fornecer aos animais uma alimentação que maximize o desempenho e a eficiência produtiva, reduzindo a deposição de gordura associada ao balanço dietético e à grande capacidade de consumo dos genótipos comerciais atuais (Lima et al., 2008).

Ainda de acordo com Lima et al. (2008), a relação ideal energia:proteína e a utilização da proteína ideal e de aminoácidos digestíveis têm grande influência no desempenho dos frangos de corte. O impacto do custo da proteína na dieta é alto, e, portanto, aumentos na sua concentração só são justificáveis quando ganhos no desempenho zootécnico ou no rendimento de carne são viabilizados. Tem sido demonstrado que ganhos zootécnicos e de rendimento de carne podem ser obtidos com o aumento da densidade proteica das dietas, independentemente da genética utilizada (Kidd et al., 2005; Vieira et al., 2007). Entretanto, existe a possibilidade de que as respostas de cada genótipo à proteína dietética sejam de magnitudes diferentes, o que indicaria a necessidade de programas nutricionais diferenciados para cada um.

Embora os genótipos existentes atualmente no mercado sejam de alto rendimento, ainda existem diferenças entre eles. Dessa forma, o rendimento de carcaça e os cortes nobres são fundamentais na escolha do genótipo que promoverá maior rentabilidade da empresa (Mendes, 2001). Pesquisas que avaliam essas características devem ser realizadas, a fim de identificar genótipos com características com bom desempenho e melhores rendimentos de carcaças e cortes nobres para permitir sua utilização nos sistemas de produção de frangos de corte.
Nesse sentido, o presente trabalho foi realizado objetivando-se comparar as características de desempenho e de carcaça de três genótipos comerciais de frangos de corte machos e fêmeas, alimentados com três dietas experimentais do nascimento aos 35 dias de idade.

\section{MATERIAL E MÉTODOS}

O experimento foi conduzido no setor de Avicultura do Departamento de Zootecnia da Universidade Federal dos Vales do Jequitinhonha e Mucuri, situado no Campus JK, em Diamantina-MG, aprovado pela Comissão de Ética no Uso de Animais (CEUA-UFVJM), sob protocolo $n^{\circ}$ 016/11.

Foram utilizados 2.970 pintos de um dia, machos e fêmeas sexados, provenientes de três genótipos comerciais de frangos de corte: Cobb 500, Hubbard Flex e Ross 308. As aves foram alojadas em galpão experimental de alvenaria com $40 \mathrm{~m}$ de comprimento, $8 \mathrm{~m}$ de largura e pédireito de $3 \mathrm{~m}$ e dividido em 90 boxes de 1,65 x $1,55 \mathrm{~m}$, com 33 aves cada. Foi utilizado o delineamento inteiramente ao acaso, em esquema fatorial $(3 \times 3 \times 2)$ : três genótipos comerciais $\mathrm{x}$ três programas nutricionais $\mathrm{x}$ dois sexos, com cinco repetições.

Foram fornecidos três programas nutricionais cujas dietas foram isocalóricas e isoproteicas, entretanto essas dietas continham diferentes concentrações de aminoácidos essenciais (lisina, metionina e metionina+cistina). Os programas nutricionais (Tab. 1, 2 e 3 ) foram formulados com base no programa nutricional basal, de acordo com as indicações de Rostagno et al. (2011): o programa nutricional com $-10 \%$ de aminoácidos (lisina, metionina e metionina+cistina) em relação ao programa nutricional basal e o programa nutricional com $+10 \%$ desses mesmos aminoácidos em relação ao basal, conforme informações de composições e digestibilidade dos ingredientes apresentados em Rostagno et al. (2011). O regime alimentar utilizado foi multifásico, aplicado a todos os programas nutricionais e dividido em três períodos: 1 a 7 dias; 8 a 21 dias e 22 a 35 dias de idade. A dieta e a água foram fornecidas à vontade. 
Desempenho e características...

Tabela 1. Composição percentual das dietas do programa nutricional basal para frangos de corte, do nascimento aos 35 dias de idade

\begin{tabular}{|c|c|c|c|}
\hline \multirow{2}{*}{ Item } & \multicolumn{3}{|c|}{ Idade (dias) } \\
\hline & 1 a 7 & 8 a 21 & 22 a 35 \\
\hline Milho moído & 57,801 & 60,319 & 61,874 \\
\hline Farelo de soja (45\% PB) & 36,329 & 33,454 & 31,440 \\
\hline Óleo de soja & 1,901 & 2,186 & 2,785 \\
\hline Fosfato bicálcico & 1,891 & 1,882 & 1,756 \\
\hline Calcário calcítico & 1,009 & 0,961 & 0,937 \\
\hline Suplemento vitamínico e mineral ${ }^{1}$ & 0,100 & 0,100 & 0,400 \\
\hline DL-metionina $(99 \%)$ & 0,315 & 0,342 & 0,315 \\
\hline L-lisina $\mathrm{HCl}(78 \%)$ & 0,289 & 0,336 & 0,204 \\
\hline Sal & 0,309 & 0,320 & 0,289 \\
\hline Total & 100,00 & 100,00 & 100,00 \\
\hline \multicolumn{4}{|c|}{ Composição nutricional estimada } \\
\hline Energia metabolizável (kcal/kg) & 3000 & 3050 & 3100 \\
\hline Proteína bruta $(\%)$ & 22,000 & 21,000 & 20,000 \\
\hline Lisina digestível (\%) & 1,260 & 1,229 & 1,079 \\
\hline Metionina digestível (\%) & 0,615 & 0,629 & 0,593 \\
\hline Metionina + cistina digestível (\%) & 0,903 & 0,906 & 0,862 \\
\hline Cálcio $(\%)$ & 0,990 & 0,961 & 0,915 \\
\hline Fósforo disponível (\%) & 0,465 & 0,460 & 0,434 \\
\hline Sódio $(\%)$ & 0,165 & 0,168 & 0,155 \\
\hline
\end{tabular}

${ }^{1}$ Suplemento vitamínico e mineral por $\mathrm{kg}$ do produto: ácido fólico ( $\mathrm{min}$ ) $175 \mathrm{mg} / \mathrm{kg}$, ácido pantotênico (min) $2500 \mathrm{mg} / \mathrm{kg}$, bacitracina de zinco $(\mathrm{min}) 13,75 \mathrm{~g} / \mathrm{kg}$, BHT $(\mathrm{min}) 1000 \mathrm{mg} / \mathrm{kg}$, biotina $(\mathrm{min}) 3,75 \mathrm{mg} / \mathrm{kg}$, cobre $(\mathrm{min})$ $2500 \mathrm{mg} / \mathrm{kg}$, colina $(\min ) 37,5 \mathrm{~g} / \mathrm{kg}$, ferro $(\min ) 12,5 \mathrm{~g} / \mathrm{kg}$, iodo $(\min ) 250 \mathrm{mg} / \mathrm{kg}$, manganês $(\min ) 17,5 \mathrm{~g} / \mathrm{kg}$, niacina (min) $75000 \mathrm{mg} / \mathrm{kg}$, salinomicina $(\mathrm{min}) 16,5 \mathrm{~g} / \mathrm{kg}$, selênio (min) $75 \mathrm{mg} / \mathrm{kg}$, vitamina A (min) $1875000 \mathrm{UI} / \mathrm{kg}$, vitamina B1 (min) $250 \mathrm{mg} / \mathrm{kg}$, vitamina B12 (min) $2500 \mathrm{mg} / \mathrm{kg}$, vitamina B2 (min) $1200 \mathrm{mg} / \mathrm{kg}$, vitamina B6 (min) $500 \mathrm{mg} / \mathrm{kg}$, vitamina D3 (min) 500.000UI/kg, vitamina E (min) 3000UI/kg, vitamina K3 (min) 450mg/kg, zinco (min) $15 \mathrm{~g} / \mathrm{kg}$.

Tabela 2. Composição percentual das dietas do programa nutricional com menos $10 \%$ de aminoácidos (lisina e metionina + cistina) em relação às dietas basais, para frangos de corte, do nascimento aos 35 dias de idade

\begin{tabular}{lccc}
\hline \multirow{2}{*}{ Item } & \multicolumn{3}{c}{ Idade (dias) } \\
\cline { 2 - 3 } & 57,249 & 8 a 20 & 21 a 34 \\
\hline Milho moído & 37,038 & 59,721 & 61,451 \\
Farelo de soja (45\%PB) & 2,092 & 34,238 & 31,965 \\
Óleo de soja & 1,886 & 2,390 & 2,936 \\
Fosfato bicálcico & 1,007 & 1,877 & 1,752 \\
Calcário calcítico & 0,100 & 0,959 & 0,936 \\
Suplemento vitamínico e mineral ${ }^{1}$ & 0,216 & 0,100 & 0,400 \\
DL-metionina (99\%) & 0,104 & 0,242 & 0,222 \\
L-lisina HCl (78\%) & 0,309 & 0,048 \\
Sal & 100,00 & 0,289 \\
\hline Total & 3000 & 100,00 \\
\hline & 22,000 & 0,319 & 3100 \\
\hline Energia metabolizável (kcal/kg) & 1,134 & 100,00 & 20,000 \\
Proteína bruta (\%) & 0,523 & 0,971 \\
Lisina digestível (\%) & 0,813 & 0,504 \\
Metionina digestível (\%) & 0,990 & 21,000 & 0,776 \\
Metionina + cistina digestível (\%) & 0,465 & 1,106 & 0,915 \\
Cálcio (\%) & 0,165 & 0,535 & 0,434 \\
Fósforo disponível (\%) & 0,815 & 0,155 \\
Sódio (\%) & 0,961 & 0,460 \\
\hline IS
\end{tabular}

${ }^{\mathrm{I}}$ Suplemento vitamínico e mineral por $\mathrm{kg}$ do produto: ácido fólico (min) 175mg/kg, ácido pantotênico (min) $2500 \mathrm{mg} / \mathrm{kg}$, bacitracina de zinco ( $\mathrm{min}) 13,75 \mathrm{~g} / \mathrm{kg}$, BHT $(\mathrm{min}) 1000 \mathrm{mg} / \mathrm{kg}$, biotina (min) 3,75mg/kg, cobre (min) $2500 \mathrm{mg} / \mathrm{kg}$, colina $(\mathrm{min}) 37,5 \mathrm{~g} / \mathrm{kg}$, ferro $(\mathrm{min}) 12,5 \mathrm{~g} / \mathrm{kg}$, iodo $(\mathrm{min}) 250 \mathrm{mg} / \mathrm{kg}$, manganês $(\mathrm{min}) 17,5 \mathrm{~g} / \mathrm{kg}$, niacina $(\min ) 75000 \mathrm{mg} / \mathrm{kg}$, salinomicina $(\mathrm{min}) 16,5 \mathrm{~g} / \mathrm{kg}$, selênio $(\mathrm{min}) 75 \mathrm{mg} / \mathrm{kg}$, vitamina A $(\mathrm{min}) 1875000 \mathrm{UI} / \mathrm{kg}$, vitamina B1 (min) $250 \mathrm{mg} / \mathrm{kg}$, vitamina B12 (min) $2500 \mathrm{mg} / \mathrm{kg}$, vitamina B2 (min) $1200 \mathrm{mg} / \mathrm{kg}$, vitamina B6 (min) $500 \mathrm{mg} / \mathrm{kg}$, vitamina D3 (min) 500.000UI/kg, vitamina E (min) 3000UI/kg, vitamina K3 (min) $450 \mathrm{mg} / \mathrm{kg}$, zinco (min) $15 \mathrm{~g} / \mathrm{kg}$. 
Tabela 3. Composição percentual das dietas do programa nutricional com mais $10 \%$ de aminoácidos (lisina e metionina + cistina) em relação às dietas basais, para frangos de corte, do nascimento aos 35 dias de idade

\begin{tabular}{|c|c|c|c|}
\hline \multirow{2}{*}{ Item } & \multicolumn{3}{|c|}{ Idade (dias) } \\
\hline & 1 a 7 & 8 a 20 & 21 a 34 \\
\hline Milho moído & 58,407 & 60,915 & 62,296 \\
\hline Farelo de soja (45\% PB) & 35,536 & 32,673 & 30,915 \\
\hline Óleo de soja & 1,695 & 1,982 & 2,634 \\
\hline Fosfato bicálcico & 1,896 & 1,888 & 1,759 \\
\hline Calcário calcítico & 1,012 & 0,964 & 0,939 \\
\hline Suplemento vitamínico e mineral ${ }^{1}$ & 0,100 & 0,100 & 0,400 \\
\hline DL-metionina (99\%) & 0,414 & 0,441 & 0,407 \\
\hline L-lisina $\mathrm{HCl}(78 \%)$ & 0,476 & 0,519 & 0,359 \\
\hline Sal & 0,310 & 0,321 & 0,290 \\
\hline Total & 100,00 & 100,00 & 100,00 \\
\hline \multicolumn{4}{|c|}{ Composição nutricional estimada } \\
\hline Energia metabolizável (kcal/kg) & 3000 & 3050 & 3100 \\
\hline Proteína bruta $(\%)$ & 22,000 & 21,000 & 20,000 \\
\hline Lisina digestível (\%) & 1,386 & 1,352 & 1,187 \\
\hline Metionina digestível (\%) & 0,709 & 0,722 & 0,681 \\
\hline Metionina + cistina digestível $(\%)$ & 0,993 & 0,996 & 0,948 \\
\hline Cálcio $(\%)$ & 0,990 & 0,961 & 0,915 \\
\hline Fósforo disponível (\%) & 0,465 & 0,460 & 0,434 \\
\hline Sódio $(\%)$ & 0,165 & 0,168 & 0,155 \\
\hline
\end{tabular}

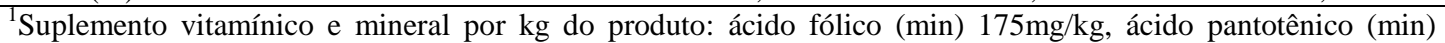
$2500 \mathrm{mg} / \mathrm{kg}$, bacitracina de zinco $(\mathrm{min}) 13,75 \mathrm{~g} / \mathrm{kg}$, BHT (min) $1000 \mathrm{mg} / \mathrm{kg}$, biotina ( $\mathrm{min}) 3,75 \mathrm{mg} / \mathrm{kg}$, cobre (min) $2500 \mathrm{mg} / \mathrm{kg}$, colina $(\min ) 37,5 \mathrm{~g} / \mathrm{kg}$, ferro $(\min ) 12,5 \mathrm{~g} / \mathrm{kg}$, iodo $(\min ) 250 \mathrm{mg} / \mathrm{kg}$, manganês $(\mathrm{min}) 17,5 \mathrm{~g} / \mathrm{kg}$, niacina $(\mathrm{min}) 75000 \mathrm{mg} / \mathrm{kg}$, salinomicina $(\mathrm{min}) 16,5 \mathrm{~g} / \mathrm{kg}$, selênio $(\mathrm{min}) 75 \mathrm{mg} / \mathrm{kg}$, vitamina A $(\mathrm{min}) 1875000 \mathrm{UI} / \mathrm{kg}$, vitamina B1 (min) 250mg/kg, vitamina B12 (min) 2500mg/kg, vitamina B2 (min) 1200mg $/ \mathrm{kg}$, vitamina B6 (min) $500 \mathrm{mg} / \mathrm{kg}$, vitamina D3 (min) $500.000 \mathrm{UI} / \mathrm{kg}$, vitamina E ( $\mathrm{min}) 3000 \mathrm{UI} / \mathrm{kg}$, vitamina K3 (min) 450mg/kg, zinco (min) $15 \mathrm{~g} / \mathrm{kg}$.

O peso corporal dos frangos foi medido ao nascer e aos 35 dias de idade. Foram registrados o consumo da dieta, o ganho de peso diário e a conversão alimentar corrigida para a mortalidade.

Aos 35 dias de idade, foram amostradas e abatidas duas aves por unidade experimental, após jejum de oito horas para avaliação do peso corporal; peso e rendimento de carcaça (constituída de cabeça e pés); peso e rendimento do peito; peso e rendimento das pernas (coxa mais sobrecoxa); peso e rendimento das asas.

As análises estatísticas foram realizadas utilizando-se o "proc GLM" do SAS (2002), segundo o modelo estatístico:

$$
\mathrm{Y}_{\mathrm{ijkl}}=\mu+\mathrm{G}_{1}+\mathrm{R}_{\mathrm{j}}+\mathrm{S}_{\mathrm{k}}+\mathrm{GR}_{\mathrm{ij}}+\mathrm{GS}_{\mathrm{ik}}+\mathrm{RS}_{\mathrm{jk}}+\mathrm{GRS}_{\mathrm{ijk}}+\mathrm{e}_{\mathrm{ijk} \mathrm{k}} \text {, }
$$

em que: $Y_{i j k l}=$ valor observado da parcela avaliada no genótipo “ $i$ ", dieta “ $j$ ” e sexo " $k$ ", na repetição " $l$ "; $\mu$ = média geral; $G_{i}=$ efeito do genótipo " $i$ " $(i=1,2,3) ; R_{j}=$ efeito do nível de aminoácidos da dieta " $j$ ” $(j=$ $1,2,3) ; S_{k}=$ efeito do sexo " $k$ " $(k=1,2) ; G R_{i j}=$ efeito da interação genótipo "i" $\times$ dieta "j"; $G S_{i k}=$ efeito da interação genótipo " $i$ " $\times$ sexo " $k$ "; $R S_{i k}=$ efeito da interação dieta " $j " \times$ sexo " $k$ "; $G R S_{i j k}=$ efeito da interação genótipo " $i " \times$ dieta “ $j " \times$ sexo " $k$ ”; e, $e_{i j k l}=$ erro aleatório associado a cada observação $Y_{i j k l}$.

\section{RESULTADOS E DISCUSSÃO}

Não houve interação tripla significativa $(\mathrm{P}>0,05)$ entre genótipo $\mathrm{x}$ dieta $\mathrm{x}$ sexo para nenhuma característica.
Houve interação significativa $(\mathrm{P} \leq 0,05)$ entre genótipo x sexo para as características de ganho de peso diário (GPD) e peso corporal aos 35 dias de idade (PC35). Aves Hubbard Flex macho apresentaram menor GPD que Cobb 500 e Ross 308 macho, e, consequentemente, quando as 
fêmeas foram avaliadas, não houve menor PC35 (Tab. 4). Não houve diferenças significativas $(\mathrm{P}>0,05)$ para GPD ou para PC35 entre os genótipos. Para todos os genótipos, os machos apresentaram médias maiores do que as fêmeas. O desempenho dos machos foi semelhante aos relatados por Moro et al. (2005) e Lima et al. (2008).

Para as demais características, tanto de desempenho quanto de carcaça, não houve interação genótipo $\mathrm{x}$ sexo, genótipo $\mathrm{x}$ dieta ou dieta x sexo.

Tabela 4. Interação significativa genótipo x sexo para ganho de peso diário (GPD) e peso corporal aos 35 dias de idade (PC35) dos frangos de corte Cobb 500, Hubbard Flex e Ross 308 do nascimento aos 35 dias de idade

\begin{tabular}{ccccc}
\hline \multirow{2}{*}{ Característica } & \multirow{2}{*}{ Sexo } & \multicolumn{3}{c}{ Genótipo } \\
\cline { 3 - 5 } & Macho & Cobb 500 & Hubbard Flex & Ross 308 \\
\hline \multirow{2}{*}{ GPD $(\mathrm{g})$} & Fêmea & $46,99 \mathrm{aA}$ & $51,90 \mathrm{aB}$ & $54,43 \mathrm{aA}$ \\
& Macho & $1967,49 \mathrm{aA}$ & $47,10 \mathrm{bA}$ & $47,95 \mathrm{bA}$ \\
\hline \multirow{2}{*}{ PC35 $(\mathrm{g})$} & Fêmea & $1673,18 \mathrm{bA}$ & $1864,83 \mathrm{aB}$ & $1952,12 \mathrm{aA}$ \\
& & & $1692,81 \mathrm{bA}$ & $1733,95 \mathrm{bA}$ \\
\hline
\end{tabular}

* Médias seguidas por distintas letras maiúsculas na mesma linha, ou minúsculas na mesma coluna (dentro da mesma característica), diferem pelo teste de Tukey a 5\% de significância.

Verificou-se efeito de genótipo $(\mathrm{P} \leq 0,05)$ para o consumo da dieta (CD). As aves Hubbard Flex apresentaram menor CD que as Cobb 500 ou as Ross 308, e estas não diferiram entre si (Tab. 5). Resultado semelhante foi encontrado para as características GPD e PC35 (Tab. 4), quando se avaliaram somente os machos, mostrando que, para as características de desempenho, os frangos Cobb 500 e Ross 308 se destacaram em relação às aves Hubbard Flex. Entretanto, para a conversão alimentar (CA), não houve diferença entre os genótipos avaliados (Tab. 5).

Tabela 5. Consumo da dieta (CD), ganho de peso diário (GPD), peso corporal (PC35) e conversão alimentar (CA) de genótipos comerciais de frangos de corte, machos e fêmeas, alimentados com diferentes programas nutricionais, do nascimento aos 35 dias de idade

\begin{tabular}{cccccc}
\hline Fator & & $\mathrm{CD}(\mathrm{g})$ & $\mathrm{GPD}(\mathrm{g})$ & $\mathrm{PC} 35(\mathrm{~g})$ & $\mathrm{CA}(\mathrm{g} / \mathrm{g})$ \\
\hline \multirow{3}{*}{ Genótipo } & Cobb 500 & $3060,95^{\mathrm{a}}$ & 50,90 & 1820,34 & $1,63^{\mathrm{a}}$ \\
& Hubbard & $2903,78^{\mathrm{b}}$ & 49,50 & 1778,82 & $1,58^{\mathrm{a}}$ \\
& Ross 308 & $3047,45^{\mathrm{a}}$ & 51,19 & 1843,04 & $1,63^{\mathrm{a}}$ \\
\hline \multirow{3}{*}{ Programa nutricional } & $-10 \%$ aa & $2965,12^{\mathrm{b}}$ & $50,14^{\mathrm{b}}$ & $1799,57^{\mathrm{b}}$ & $1,61^{\mathrm{a}}$ \\
& Basal & $3137,44^{\mathrm{a}}$ & $52,45^{\mathrm{a}}$ & $1877,50^{\mathrm{a}}$ & $1,62^{\mathrm{a}}$ \\
& $+10 \%$ aa & $2909,61^{\mathrm{b}}$ & $49,00^{\mathrm{b}}$ & $1765,12^{\mathrm{b}}$ & $1,61^{\mathrm{a}}$ \\
\hline \multirow{2}{*}{ Sexo } & Macho & $3107,08^{\mathrm{a}}$ & 53,77 & 1928,15 & $1,58^{\mathrm{b}}$ \\
& Fêmea & $2901,03^{\mathrm{b}}$ & 47,29 & 1699,98 & $1,65^{\mathrm{a}}$ \\
\hline $\mathrm{CV}(\%)$ & & 6,81 & 4,10 & 3,71 & 5,50 \\
\hline
\end{tabular}

* Médias na mesma coluna, dentro de cada fator, seguidas por distintas letras, diferem pelo teste de Tukey a 5\% de significância.

$-10 \%$ aa - dieta com menos $10 \%$ de aminoácidos (lisina e metionina+cistina) que a dieta basal; $+10 \%$ aa - dieta com mais $10 \%$ de aminoácidos (lisina e metionina+cistina) que a dieta basal.

$\mathrm{CV}$ - coeficiente de variação.

As aves alimentadas com dieta basal apresentaram melhores desempenhos para CD, GPD e PC35, e não se observaram diferenças significativas para a conversão alimentar dos frangos, à semelhança dos resultados obtidos por Abdel-Maksoud et al. (2010) e Vasconcellos et al. (2010), que encontraram diferenças significativas nas características de desempenho de frangos de corte alimentados com diferentes níveis de proteína bruta na dieta. De acordo com D’Mello (1993), o consumo da dieta desbalanceada altera a concentração dos aminoácidos no plasma e nos tecidos, resultando em redução no consumo e no crescimento do animal. Ainda segundo D'Mello (1993), o desbalanceamento de aminoácidos na dieta pode 
resultar em alterações no consumo dos animais. Considerando o relato de D'Mello (1993) e o fato de as aves terem recebido dietas isoenergéticas, pode-se inferir que os programas nutricionais com $+10 \%$ e $-10 \%$ de aminoácidos diminuíram o consumo e o peso corporal das aves aos 35 dias de idade. De acordo com Sklan e Plavnik (2002), a redução do crescimento pode ser atribuída a quantidades limitadas de aminoácidos disponíveis na dieta, uma vez que frangos de corte de alto potencial genético para deposição de carne magra na carcaça possuem maior exigência de aminoácidos em todas as fases. Ainda, D'Mello (1993) relata que, para haver síntese proteica, é necessário que todos os aminoácidos, essenciais e não essenciais estejam presentes. Assim, o desbalanceamento entre os aminoácidos pode reduzir a eficiência de utilização deles, alterando a deposição de proteína corporal.

Os machos apresentaram melhor desempenho em relação às fêmeas para $\mathrm{CD}$ e $\mathrm{CA}$ (Tab. 5), independentemente do genótipo, resultado semelhante ao obtido, também, para GPD e PC35 (Tab. 4), quando desdobrado o efeito da interação genótipo x sexo.

Não houve efeito $(\mathrm{P}>0,05)$ do genótipo sobre peso corporal ao abate, peso da carcaça, rendimento da carcaça e peso das pernas (Tab. 6). Entretanto, houve diferenças significativas $(\mathrm{P} \leq 0,05)$ entre os genótipos para peso do peito, rendimento do peito, rendimento das pernas, peso das asas e rendimento das asas. Embora não houvesse diferenças entre genótipos para peso e rendimento de carcaça, houve diferenças para as características de rendimento de cortes. Esses resultados evidenciam diferenças entre genótipos para cortes nobres, o que poderia interferir na escolha do genótipo que melhor atenda às demandas específicas de mercado. Mendes (2001) e Fernandes et al. (2001) também não observaram diferenças para o rendimento de carcaça ao avaliarem diferentes genótipos de frangos de corte.

As aves dos genótipos Cobb 500 e Ross 308 apresentaram maiores peso e rendimento do peito. Por outro lado, as aves do genótipo Hubbard Flex apresentaram maior rendimento de pernas. Com relação ao peso e ao rendimento das asas, as aves Hubbard Flex apresentaram as maiores médias, não diferindo das aves do genótipo Ross 308, que, por sua vez, não diferiu das aves Cobb 500. Essa diferença entre genótipos para características de carcaça é importante na escolha dos genótipos que atendam às exigências do mercado que se pretende atingir.

Observou-se efeito dos programas nutricionais $(\mathrm{P} \leq 0,05)$ sobre peso corporal ao abate, peso e rendimento da carcaça, peso do peito, das pernas e das asas. Aves alimentadas com dieta basal mostraram, de modo geral, melhor desempenho do que as demais. Não se verificou efeito das dietas para rendimentos do peito, das pernas e das asas (Tab. 6). Lima et al. (2008) não encontraram efeito dos níveis de energia das dietas sobre o rendimento de peito em frangos. Esses mesmos autores relataram, ainda, que o maior rendimento de peito foi observado quando os frangos foram alimentados com altos níveis de aminoácidos, corroborando os relatos de Wijtten et al. (2004), que observaram que níveis mais altos de treonina e lisina aumentaram o rendimento de peito dos frangos. Vasconcellos et al. (2010) não encontraram efeito dos níveis de proteína bruta da dieta sobre o rendimento de carcaça, coxa, asas e dorso; em contrapartida, esses mesmos autores verificaram efeito significativo para o rendimento de peito. Outros autores, como Kamram et al. (2008) e Rodrigues et al. (2008), não encontraram diferenças estatísticas para rendimento de carcaça e cortes de frangos alimentados com diferentes níveis de proteína bruta na dieta.

Os machos apresentaram maiores $(\mathrm{P}<0,05)$ peso corporal ao abate, peso de carcaça e pesos de peito, pernas e asas em relação às fêmeas. Não se verificou efeito de sexo sobre os rendimentos de carcaça, peito, pernas e asas (Tab. 6), resultados que diferem dos obtidos por Lima et al. (2008), que sugerem efeito de sexo sobre os rendimentos de carcaça e cortes nobres.

Os efeitos significativos do sexo sobre características de carcaças e de desempenho reforçam a importância das práticas de criação em sexos separados, visando à obtenção de melhores desempenhos na criação dos frangos. 
Desempenho e características...

Tabela 6. Características de carcaça de três genótipos comerciais de frangos de corte, machos e fêmeas, alimentados com diferentes programas nutricionais, aos 35 dias de idade

\begin{tabular}{|c|c|c|c|c|c|c|c|c|c|}
\hline Fator & $\begin{array}{l}\text { Peso Corporal } \\
\text { ao abate (g) }\end{array}$ & $\begin{array}{c}\text { Peso da } \\
\text { Carcaça (g) }\end{array}$ & $\begin{array}{c}\text { Rendimento da } \\
\text { Carcaça }(\%)\end{array}$ & $\begin{array}{l}\text { Peso do } \\
\text { Peito } \\
(\mathrm{g})\end{array}$ & $\begin{array}{l}\text { Rendimento do } \\
\text { Peito } \\
(\%)\end{array}$ & $\begin{array}{l}\text { Peso das } \\
\text { Pernas }(\mathrm{g})\end{array}$ & $\begin{array}{l}\text { Rendimento das } \\
\text { Pernas }(\%)\end{array}$ & $\begin{array}{l}\text { Peso das } \\
\text { Asas } \\
(\mathrm{g})\end{array}$ & $\begin{array}{c}\text { Rendimento } \\
\text { das Asas } \\
(\%)\end{array}$ \\
\hline \multicolumn{10}{|l|}{ Genótipo } \\
\hline Cobb 500 & $1842,64 a$ & $1517,17 \mathrm{a}$ & $82,31 \mathrm{a}$ & $517,87 \mathrm{a}$ & $34,01 \mathrm{a}$ & $381,10 \mathrm{a}$ & $25,14 \mathrm{~b}$ & $134,63 \mathrm{~b}$ & $8,89 \mathrm{~b}$ \\
\hline Ross 308 & $1919,53 a$ & $1560,63 \mathrm{a}$ & $81,31 \mathrm{a}$ & $516,13 \mathrm{a}$ & $33,00 \mathrm{a}$ & $388,23 \mathrm{a}$ & $24,84 \mathrm{~b}$ & $140,17 \mathrm{ab}$ & $9,01 \mathrm{ab}$ \\
\hline \multicolumn{10}{|c|}{ Programa Nutricional } \\
\hline$-10 \%$ aa. & $1857,69 \mathrm{~b}$ & $1513,47 \mathrm{~b}$ & $81,19 \mathrm{~b}$ & $494,43 b$ & $32,60 \mathrm{a}$ & $389,23 \mathrm{ab}$ & $25,72 \mathrm{a}$ & $139,63 \mathrm{ab}$ & $9,24 \mathrm{a}$ \\
\hline \multicolumn{10}{|l|}{ SEXO } \\
\hline Macho & 1998,40a & $1635,89 \mathrm{a}$ & $81,86 \mathrm{a}$ & $543,00 \mathrm{a}$ & $33,16 \mathrm{a}$ & $421,49 \mathrm{a}$ & $25,76 \mathrm{a}$ & $149,00 \mathrm{a}$ & $9,12 \mathrm{a}$ \\
\hline Fêmea & $1746,98 \mathrm{~b}$ & $1425,33 \mathrm{~b}$ & $81,61 \mathrm{a}$ & $463,73 \mathrm{~b}$ & $32,45 \mathrm{a}$ & $359,44 \mathrm{~b}$ & $25,24 \mathrm{a}$ & $130,75 \mathrm{~b}$ & $9,18 \mathrm{a}$ \\
\hline CV (\%) & 7,01 & 7,16 & 2,04 & 10,98 & 6,73 & 10,52 & 8,41 & 11,06 & 10,47 \\
\hline
\end{tabular}

* Médias na mesma coluna, dentro de cada fator, seguidas por distintas letras, diferem pelo teste de Tukey a 5\% de significância.

$-10 \%$ aa - dieta com menos $10 \%$ de aminoácidos (lisina e metionina+cistina) que a dieta basal $+10 \%$ aa - dieta com mais $10 \%$ de aminoácidos (lisina e metionina+cistina) que a dieta basal. CV - coeficiente de variação.

\section{CONCLUSÕES}

O desempenho dos frangos de corte Cobb 500 e Ross 308 foi maior do que frangos Hubbard Flex aos 35 dias de idade. Frangos alimentados com o programa nutricional basal apresentaram maior desempenho. Machos apresentaram melhores desempenhos que as fêmeas.

\section{AGRADECIMENTOS}

Os autores agradecem o principal idealizador deste trabalho, o professor Aldrin Vieira Pires (in memorian), pela sua imensa contribuição científica na execução e redação deste trabalho e o apoio recebido da Capes, do $\mathrm{CNPq}$ e da Fapemig.

\section{REFERÊNCIAS}

ABDEL-MAKSOUD, A.; YAN, F.; CERRATE, S. et al. Effect of Dietary Crude Protein, Lysine Level and Amino Acid Balance on Performance of Broilers 0 to 18 Days of Age. Int. J. Poult. Sci., v.9, p.21-27, 2010.

D'MELLO, J.P.F. Amino acids in animal nutrition. 2.ed. Edinburg: CABI, 2003. 544p.

FERNANDES, L.M.; VIEIRA, S.L.; KINDLEIN, G. et al. Avaliação do crescimento e rendimento de carcaça de linhagens comerciais e dois tipos de bebedouro. Bras. J. Poultry Sci., v.3, supl., p.1, 2001.
KAMRAN, Z.; SARWAR, M.; NISA, M. et al. Effect of low-protein diets having constant energy-to-protein ratio on performance and carcass characteristics of broiler chickens from one to thirty-five days of age. Poult. Sci., v.87, p.468-474, 2008.

KIDD, M.T.; CORZO A.; HOEHLER, D. et al. Broiler responsiveness (Ross $\mathrm{x}$ 708) to diets varying in amino acid density. Poult. Sci., v.84, p.1389-1396, 2005.

LIMA, L.M.B.; LARA, L.J.C.; BAIÃO, N.C. et al. Efeitos dos níveis de energia, lisina e metionina + cistina sobre o desempenho e o rendimento de carcaça de frangos de corte. Rev. Bras. Zootec., v.37, p.1424-1432, 2008.

MENDES, A.A. Rendimento e qualidade da carcaça de frangos de corte. In: CONFERÊNCIA APINCO DE CIENCIA E TECNOLOGIA AVICOLAS, 2001, Campinas. Anais... Campinas: APINCO, 2001. p.79-99.

MOREIRA, J.; MENDES, A.A.; ROÇA, R.O. et al. Efeito da densidade populacional sobre desempenho, rendimento de carcaça e qualidade da carne em frangos de corte de diferentes linhagens comerciais. Rev. Bras. Zootec., v.33, p.1506-1519, 2004.

MORO, D.N.; ZANELLA, I.; FIGUEIREDO, E.A.P. et al. Desempenho produtivo de quatro linhagens de frango de corte. Cienc. Rural, v.35, p.446-449, 2005. 
RODRIGUES, K.F.; RODRIGUES, P.B.; FREITAS, R.T.F. et al. Desempenho e rendimento de carcaça de frangos de corte no período de 22 a 42 dias de idade alimentados com dietas contendo diferentes relações lisina digestível:proteína bruta. Rev. Bras. Zootec., v.37, p.645-652, 2008.

ROSTAGNO, H.S.; ALBINO, L.F.T.; DONZELE, J.L. et al. Tabelas brasileiras para aves e suínos: composição de alimentos $\mathrm{e}$ exigências nutricionais. 3.ed. Viçosa, MG: Universidade Federal de Viçosa, 2011. 252p.

SANTOS, A.L.; SAKOMURA, N.K.; FREITAS, E.R. et al. Estudo do crescimento, desempenho, rendimento de carcaça e qualidade de carne de três linhagens de frango de corte. Rev. Bras. Zootec., v.34, p.1589-1598, 2005.

STATISTICAL analysis systems: user's guide. Version 9.1. Cary: SAS, 2002. v.2, 1052p.

SKLAN, D.; PLAVNIK, I. Interactions between dietary crude protein and essential amino acid intake on performance in broilers. Brit. Poult. Sci., v.43, p.442-449, 2002.
VASCONCELLOS, C.H.F.; FONTES, D.O.; VIDAL, T.Z.B. et al. Efeito de diferentes níveis de proteína bruta sobre o desempenho e composição de carcaça de frangos de corte machos de 21 a 42 dias de idade. Cienc. Agrotec., v.34, p.1039-1048, 2010.

VIEIRA, S.L.; OLMOS, A.R.; BERRES, J. et al. Respostas de frangos de corte fêmeas de duas linhagens a dietas com diferentes perfis protéicos ideais. Cienc. Rural, v.37, p.1753-1759, 2007.

WIJTTEN, P.J.A.; LEMME, A.; LANGHOUT, D.J. Effects of different dietary ideal protein levels on male and female broiler performance during different phases of life: single phase effects, carryover effects, and interactions between phases. Poult. Sci., v.83, p.2005-2015, 2004. 